\title{
Desarrollo sostenible: compromiso de toda la sociedad
}

\section{Sustainable development: a commitment from the whole society}

\author{
Luz Eugenia Alzate Cadavid \\ Dirección Operativa de Investigación, Institución Universitaria Pascual Bravo, Medellín, Colombia. \\ luz.alzate@pascualbravo.edu.co
}

Recibido: junio 22, 2018. Aceptado: junio 30, 2018.

La Asamblea General de las Naciones Unidas adoptó en septiembre de 2015 la Agenda 2030 para estimular durante los próximos 15 años la acción en favor de las personas, el planeta, la prosperidad, la paz y las alianzas para su implementación, esferas de importancia crítica para la humanidad y el planeta, reconociendo que la erradicación de la pobreza en todas sus formas y dimensiones, es el mayor desafío que enfrenta el mundo y constituye un requisito indispensable para el desarrollo sostenible [1].

Una buena noticia y esperanzadora para nuestro planeta y las futuras generaciones, es que, en el mundo, lo cual no es ajeno nuestro país, desde los diferentes niveles del gobierno, así como sus entidades tanto públicas como privadas, se viene presentando un marcado interés por adaptar sus políticas y planes de desarrollo a los Objetivos de Desarrollo Sostenible (ODS), como un llamado a la adopción de medidas para poner fin a la pobreza, proteger el planeta y garantizar que todas las personas gocen de paz y prosperidad.

Son 17 Objetivos, 169 metas y 231 indicadores que incluyen nuevas dimensiones como el cambio climático, la desigualdad económica, la innovación, el consumo sostenible, la paz y la justicia, entre otras prioridades. La responsabilidad no puede ser solo de los Jefes de Estado y de Gobierno; es un compromiso que debe involucrar nuevos actores del desarrollo como el sector privado, la juventud, la sociedad civil y la academia, entre otros, y en esta colaboración juega un papel muy importante la educación superior, la investigación científica y por supuesto nuestros investigadores que unidos en sinergia y compartiendo recursos, puedan lograr un cambio positivo en beneficio de la humanidad y el planeta.

Hago un llamado a nuestros investigadores, docentes y estudiantes, a aprovechar sus potencialidades, su interés por la investigación y las capacidades institucionales para que se vinculen con este propósito, encaminando sus esfuerzos desde sus proyectos de investigación a poner su grano de arena y aportar a la solución de los problemas y necesidades, cada vez más crecientes, de nuestra sociedad.

Invito a la comunidad de investigación a estudiar y profundizar en estos objetivos, para que, desde las aulas, los semilleros y los grupos de investigación se involucre a los jóvenes a pensar un mundo mejor, provocando su interés por la investigación si queremos que se produzcan cambios profundos en la sociedad.

\section{REFERENCIAS}

[1] CEPAL, «Agenda 2030 y los Objetivos de Desarrollo Sostenible: una oportunidad para América Latina y el Caribe,» Comisión Económica para América Latina y el Caribe, Santiago de Chile, 2018

\section{Citar como:}

L.E. Alzate. "Desarrollo sostenible: compromiso de todos los estamentos de la sociedad" Revista CINTEX, Vol. 23(1), pp. 10. 2018. 